Article

\title{
Interveillance: A New Culture of Recognition and Mediatization
}

\author{
André Jansson \\ Department of Geography, Media and Communication, Karlstad University, 65188 Karlstad, Sweden; \\ E-Mail: andre.jansson@kau.se
}

Submitted: 30 April 2015 | In Revised Form: 7 July 2015 | Accepted: 23 July 2015 |

Published: 20 October 2015

\begin{abstract}
The everyday uses of networked media technologies, especially social media, have revolutionized the classical model of top-down surveillance. This article sketches the contours of an emerging culture of interveillance where nonhierarchical and non-systematic monitoring practices are part of everyday life. It also introduces a critical perspective on how the industrial logics of dominant social media, through which interveillance practices are normalized, resonate with social forces already at play in individualized societies. The argument is developed in three steps. Firstly, it is argued that the concept of interveillance is needed, and must be distinguished from surveillance, in order to critically assess the everyday mutual sharing and disclosure of private information (of many different kinds). Secondly, it is argued that the culture of interveillance responds to the social deficit of recognition that characterizes highly individualized societies. Finally, it is argued that the culture of interveillance constitutes a defining instance and even represents a new stage of the meta-process of mediatization. The dialectical nature of interveillance integrates and reinforces the overarching ambiguities of mediatization, whereby the opportunities for individuals and groups to achieve growing freedom and autonomy are paralleled by limitations and dependences vis-à-vis media.
\end{abstract}

\section{Keywords}

identity; interveillance; mediatization; recognition; social media; surveillance

\section{Issue}

This article is part of the special issue "Surveillance: Critical Analysis and Current Challenges", edited by James Schwoch (Northwestern University, USA), John Laprise (Independent Researcher) and Ivory Mills (Northwestern University, USA).

(C) 2015 by the author; licensee Cogitatio (Lisbon, Portugal). This article is licensed under a Creative Commons Attribution 4.0 International License (CC BY).

\section{Introduction}

In the last decade we have seen the arrival of what might be considered a new stage in the history of mediatization. The parallel expansion of social media, mobile media devices and various lifestyle applications constitutes more than a technological shift. It also denotes a social and cultural shift through which more and more areas of social life become saturated with and dependent on processes of mediation. There are today mobile applications for almost any kind of lifestyle practice, through which activities can be measured, stored and shared. At first sight the growing tendency to monitor, quantify and comment on one's own life as well as those of others may seem like a mediainvoked transformation following certain technologi- cally enabled and commercially driven logics of social media industries (van Dijck \& Poell, 2013). However, the emergence and significance of such logics should also be understood in relation to social forces that have long prevailed in modern society and can be traced to broader structural transformations, above all individualization.

In this mainly theoretical essay, the key idea that will be elaborated on is that we (that is, those of us who live in societies marked by digital media abundance) are immersed in a culture of interveillance. This perspective provides a way of capturing the social embeddedness of contemporary surveillance processes, typically governed by commercial forces, while at the same time recognizing the non-hierarchical and nonsystematic nature of most social monitoring processes 
occurring in everyday life. It is also a way of pointing out what is new about contemporary mediatization; how the industrial logics of dominant social media resonate with the everyday social characteristics of individualized modern society. Mediatization is basically understood as a historical meta-process whereby a variety of social realms, in organizational settings as well as everyday life, become increasingly adapted to and dependent upon media technologies and institutions (see, e.g., Couldry \& Hepp, 2013; Krotz, 2007; Lundby, 2014).

Starting out from these fundamental assumptions, my aim is to explore three interconnected arguments, each constituting a separate section of the text. Firstly, it will be argued that the concept of interveillance is needed in order to critically assess the everyday mutual sharing and disclosure of private information (of many different kinds) that constitutes an increasing share of all media practices. The concept is needed not only for defining particular forms of mediated interaction, namely those forms marked by digital connectivity (van Dijck, 2012, 2013), but also more indirectly in order to preserve the conceptual specificity and critical potential of the term surveillance. In the first part of the essay the properties of interveillance will be discussed in relation to related concepts, notably lateral surveillance (Andrejevic, 2005) and social surveillance (Marwick, 2012).

Secondly, it will be argued that the culture of interveillance responds to the social deficit of recognition that characterizes highly individualized societies. Interveillance breeds in the soils of an other-directed social landscape that had already been diagnosed in the mid $20^{\text {th }}$ century by sociologists like David Riesman (1950) and later by Giddens (1991) and Beck and Beck-Gernsheim (2002), amongst others. The second part of the essay will, through an engagement with Axel Honneth's (2012) theory of recognition, discuss the ways in which dominant forms of social media and accompanying representational spaces of interveillance largely reinforce this sense of lack, while at the same time circulating promises of mutual recognition and individual growth. This is to say that the culture of interveillance holds a dialectical character where striving for recognition coalesces with social simulations that bind individuals closer to technological and commercial structures of dependence.

Thirdly, by way of conclusion, it will be argued that the culture of interveillance constitutes a defining instance of contemporary mediatization. The dialectical nature of interveillance integrates and reinforces the overarching ambiguities of mediatization, whereby the opportunities for individuals and groups to achieve growing freedom and autonomy are paralleled by limitations and dependences vis-à-vis media. Interveillance constitutes an entry point for grasping how new forms of normalized media dependence are replacing and displacing pre-established patterns tied to the mass media era. Interveillance gives us an analytical tool for conducting critical analyses of how the dialectics of mediatization are played out and socially constructed at the level of everyday life.

This article should also make an epistemological contribution to the mediatization debate. Whereas mediatization research has been accused of being media-centric, that is, explaining social transformations too much in terms of media change (see Deacon \& Stanyer, 2014), my analysis adheres to the broadly accepted view of mediatization as concerned with the interplay between media, culture and society (see, e.g., Hepp, 2013; Hepp, Hjarvard, \& Lundby, 2015; Krotz, 2007). Through the concept of interveillance, which articulates the fundamental role of long-term social transformations like individualization in conditioning media change, the aim is to stress the continuously contested and socially moulded nature of mediatization (Jansson, forthcoming). In addition, the dialectical understanding of mediatization paves the way for rethinking mediatization as a research programme for immanent critique. Mediatization is at its strongest when it captures the inherent and continuously evolving social contradictions and ambivalences that mark out media saturated societies, notably in terms of liberating versus constraining forces. Accordingly, the dialectical perspective needs to move beyond and build bridges between the predominant social-constructivist and institutionalist frameworks (see Couldry \& Hepp, 2013). In the more confined analysis of interveillance the combination of recognition theory (Honneth, 2012) and theorizations of emerging "social media logics" (van Dijck \& Poell, 2013) constitutes one such bridge.

\section{Interveillance and the Social Relocation of Media}

One thing that distinguishes our contemporary media landscape from what it looked like just one or two decades ago is the social location of media. In addition to their traditional position between people and various organizational entities (including media institutions) that characterized the mass media landscape (see Hjarvard, 2013, pp. 23-27), media technologies are now to a greater extent located between people. This is not to say that interpersonal media are all new; telephony and the postal system have been crucial to the history of modernity. Nor is it to say that today's networked media, enabling various forms of many-to-many communication, have replaced mass media; rather these forms co-exist and interact in various ways, giving rise to increasingly complex media landscapes. If we are to understand the consequences of mediatization at the level of social life, that is, how various lifestyle sectors (Giddens, 1991) are successively made dependent on and adapted to certain technologies and institutions of mediation (Jansson, 2013), we must account for this multi-layeredness while at the same time disentangling what is succinctly new about the current situation. 
A relevant framework for identifying the novelty of our networked media landscape is suggested by van Dijck and Poell (2013), who introduce four elements of what they call "social media logic": programmability, popularity, connectivity and datafication. Whereas the whole idea of any coherent "media logic(s)" should be treated with great caution, it is fair to argue that there exist processes at the industrial level of media circulation that are built into the very techno-economic architecture. As Hepp (2013, p. 46) points out in a critique of media logic(s), "in the functionalities of media logic we no longer see the acting subjects, the meaningfulness of their action, as well as all the other problems of power in communication". This is important. In adopting van Dijck and Poell's (2013) notion of social media logics it should not be inferred that mediatization follows any clear-cut social logic(s), but that there are certain industrial mechanisms that follow calculated orders, notably algorithms, for profit maximisation. These mechanisms respond to and reinforce the social behaviour of media users, and can be located in a particular area of the digital media landscape, which may be called dominant social media. Such media may take the form of websites or mobile applications and involve social networking sites (e.g., Facebook, Linkedln), video sharing sites (e.g., YouTube), blogs and microblogs (e.g., Twitter, Weibo), as well as social media extensions of various lifestyle applications (e.g., RunKeeper, Nike+). What they have in common is that they turn "platformed sociality" (van Dijck, 2013, p. 4) into economic value through the development and implementation of industrial logics (see also Gillespie, 2010; Striphas, 2015).

This is not the place for going deeper into each of the four elements suggested by van Dijck and Poell (2013). Instead, two general points will be advanced, related foremost to popularity and connectivity that are particularly important for describing how industrial logics play into the on-going social relocation of media, which will also lead us further to the question of interveillance. Firstly, van Dijck and Poell (2013, pp. 6-7) stress that the implementation of various measurements of popularity, such as the Like-mechanism, constitutes the extension of economic drivers that were already at place in commercial mass media settings in the shape of, for instance, top lists and ratings. The difference today is that individual media users may also take part in this competition for popularity, where the automated generation of friend stats on Facebook and follower counts on Twitter becomes, for instance, a means of expressing social integration and success. At the same time, media users are turned into (unpaid) "prosumers" of media content and the social media industry is given raw material for generating economic turnover through advertising sales (see also Fuchs, 2014, Ch. 5).

Secondly, van Dijck and Poell (2013, pp. 8-9) intro- duce a crucial distinction between connectivity and connectedness. Whereas connectedness is all about the meaningful social connections between individuals and groups - which social media promote and which various media have enhanced and extended in different ways since their very origin-connectivity refers to "the socio-technological affordance of networked platforms to connect content to user activities and advertisers" (van Dijck \& Poell, 2013, p. 8). This means that the social practices that these platforms mediate are actually not as free and open-ended as one might think, but partly governed and exploited via the algorithms of the techno-economic architecture (see also Striphas, 2015). In everyday life the distinction between connectivity and connectedness becomes difficult to identify since, for instance, many close relations may also be exploited and reproduced via automated connective processes, and vice versa. The important point is precisely this accentuated fuzziness between connectedness and connectivity - the fact that social relations are to a certain extent premediated and simulated through automated patterns of connectivity. These concepts will be further explored below.

Accordingly, the elements of popularity and connectivity reinforce one another; connectivity operates as a support for reaching the goal of popularity. In more straightforward terms, this development can be described as an escalating commoditization of social life, which today expands beyond the confines of particular groups and particular forms of communication (see, e.g., Fuchs, 2014, Ch. 5). In transmedia environments, where information flows smoothly between different platforms and devices, almost any kind of everyday practice can be measured, recorded and circulated/shared, and thus commoditized, as information either through embedded social functionalities of applications such as RunKeeper, or through external sharing via, for example, Facebook or Instagram. The industrial logics of social media stimulate their users/prosumers to think of their peers, whether close friends or more distant acquaintances, as audiences of their own lifestyle performances (see Marwick, 2013; Marwick \& boyd, 2011; Turkle, 2011). In this way, dominant social media are part of gradually normalizing new forms of reflexivity and new ways of relating to the social world. As we will see, however, the identification of "social media logics" at the industrial level should not lead us to adopt a media-centric view of social transformations.

Surveillance is part and parcel of these alterations. Whilst mass media institutions have long conducted or consulted various kinds of audience research in order to increase the popularity of media products and sell audience segments to advertisers, digital media platforms enable datafication and automated, or interactive, surveillance (see Andrejevic, 2007). Datafication implies that media industries as well as other commer- 
cial actors are able to retrieve advanced profiles of the market and automatically target their advertising, even on a real-time basis, through instantaneous analysis of user generated data streams (Striphas, 2015; Trottier, 2011; Trottier \& Lyon, 2012). Digital transmedia technologies thus revolutionize the classical model of topdown surveillance, defined as the systematic collation and analysis of information in order to exercise power over a certain population or territory (see, e.g., Giddens, 1987, pp. 14-15; Lyon, 2007, p. 14). Furthermore, several researchers have pointed out that surveillance expands beyond administrative settings (economy and state) and in various ways has come to saturate social life in the form of peer-to-peer monitoring (e.g., Andrejevic, 2005). This tendency should be seen in light of the aforementioned relocation process, through which individuals and groups start relating to themselves more and more as manageable symbolic entities, even brands (see Marwick, 2013).

These diagnoses of technologically- and industriallydriven social change should certainly inform a critical view of mediatization. However, they suffer from a recurring dilemma when it comes to conceptual stringency. When applying the term surveillance to the analysis and understanding of more horizontal processes of information gathering and disclosure one runs the risk of misnaming and simplifying aspects of social life that are dense with social and cultural ambivalences. For instance, the concept of lateral surveillance, introduced by Andrejevic (2005), refers to "peer-to-peer monitoring, understood as the use of surveillance tools by individuals, rather than by agents of institutions, public or private, to keep track of one another" (Andrejevic, 2005, p. 488). The basic argument is that the expanding availability of new online technologies has also fostered a socio-cultural climate where people get accustomed to checking up on others in order to avoid risk, for example in relation to new romantic interests. Whereas Andrejevic points to a significant new area of communicational practice, it is difficult to distinguish to what extent and in which particular cases this type of peer-to-peer monitoring falls under the original definition of surveillance. The kinds of "check-ups" that Andrejevic discusses are often far from systematic and may be more acquainted with everyday social phenomena driven by affection and curiosity, even a desire for knowledge. They also, literally, contradict the hierarchical relations that originally used to define surveillance. Albrechtslund (2008), who proposes the concept of participatory surveillance for analyzing similar monitoring practices, even sees this as a potential source of social empowerment among "ordinary" or disadvantaged groups of people-a conclusion that contradicts Andrejevic's more critical view.

Similarly, Marwick's (2012) notion of social surveillance, which refers to the social media practices of "closely examining content created by others and look- ing at one's own content through other people's eyes" (Marwick, 2012, p. 378), problematizes the power dynamics associated with surveillance. Her point is that even though social surveillance is marked by reciprocity-that is, when people give away information they expect to get something back -it can still be framed by the notion of surveillance, because it leads to selfmanagement among social media users through the "internalization of the surveilled gaze" (Marwick, 2012, p. 381). Even sharing Marwick's understanding of how social surveillance is entangled with everyday power relations, informed by Foucault's (1977) notion of capillaries of power, two main problems may be detected. Firstly, much empirical research shows that the kinds of practices that Marwick highlights are not often systematically undertaken, but rather occur within the realm of more or less floating everyday routines (see, e.g., Christensen, 2014; Humphreys, 2011; Jansson, 2014a). When self-monitoring practices escalate into well thought out strategies for improving one's reputation or performance, such as among amateur bloggers and in certain media related professions or among adherents of the Quantified Self movement, one might probably speak of systematic procedures, and thus surveillance in the stricter sense. But these groups constitute quite exceptional cases and thus contradict Marwick's depiction of social surveillance as a widespread phenomenon related to social media in general.

Secondly, when speaking of the internalization of the surveilled gaze, what Marwick outlines is largely a technologically driven cultivation process, akin to Andrejevic's thoughts on how the spread of new surveillance tools instils new forms of behaviour among ordinary people. Also if we would agree on the idea that monitoring practices enabled by dominant social media are to be seen as a particular kind of surveillance we should be cautious about placing all social media use under the same rubric. Whereas the industrial logics of social media, and the elements of connectivity and popularity in particular, may sustain a drive towards more open-ended forms bonding, as identified already in Wittel's (2001) analyses of network sociality, studies also show that social media (just like other technologies) are appropriated in culturally specific ways (e.g., Christensen, 2014; Jansson, 2014a).

We thus need a concept that allows for complex analyses of the social processes related to mediated monitoring and control-without emptying out the original meaning and critical potential of the term surveillance. What may be termed interveillance resembles closely the phenomena outlined by Andrejevic, Albrechtslund and Marwick. ${ }^{1}$ Interveillance includes the

\footnotetext{
${ }^{1}$ Another concept that has been juxtaposed with surveillance is sousveillance, coined by artist Steve Mann. However, sousveillance should be seen as a deliberate reaction to surveillance processes, involving highly reflexive and technologically
} 
kinds of everyday check-ups that Andrejevic discusses, as well as Albrechtslund's more expressively oriented practices and the anticipation of other people's mediated gazes. Interveillance also includes the normalization of horizontal networking practices that Marwick refers to. Interveillance means that social agents to a growing extent come to understand and define the relations between themselves and others via automatically generated recommendations of contacts and commodities (connectivity) and quantified simulations of social status (popularity). Interveillance practices are thus inseparable from societal surveillance processes, foremost algorithmically based commercial surveillance (datafication), but they are not systematic and hierarchical per se. Rather, they are driven by the fundamental social needs through which identities are (re)created and manifested, and thus take on a relatively non-reflexive and volatile character (see Table 1).

Table 1. Analytical distinctions between surveillance and interveillance.

\begin{tabular}{|c|c|c|}
\hline & Surveillance & Interveillance \\
\hline Driving force & $\begin{array}{l}\text { Control of } \\
\text { people and } \\
\text { spaces }\end{array}$ & $\begin{array}{l}\text { Identity } \\
\text { development }\end{array}$ \\
\hline $\begin{array}{l}\text { Mode of } \\
\text { practice }\end{array}$ & $\begin{array}{l}\text { Systematic } \\
\text { procedures }\end{array}$ & $\begin{array}{l}\text { Everyday } \\
\text { routines }\end{array}$ \\
\hline Power relation & $\begin{array}{l}\text { Hierarchical, } \\
\text { formal }\end{array}$ & $\begin{array}{l}\text { Multi-layered, } \\
\text { informal }\end{array}$ \\
\hline $\begin{array}{l}\text { Direction of } \\
\text { flows }\end{array}$ & $\begin{array}{l}\text { Mainly one- } \\
\text { way, vertical }\end{array}$ & $\begin{array}{l}\text { Mainly two- } \\
\text { way, horizontal }\end{array}$ \\
\hline
\end{tabular}

Furthermore, to the extent that interveillance practices become part of everyday life, they do not look the same and do not involve the same media in all social groups and in all walks of life. This means that if we want to grasp the culture of interveillance as a broader and socially complex transformation we have to combine media-centric models of altered "media logics", understood as industrial modes of accumulation as discussed above, with historically contextualized understandings of socio-cultural structures and their transformation. In the following section attention will turn to Honneth's (2012) theory of recognition in order to outline a critical perspective through which the social nature and historical development of interveillance can be further explicated and problematized. Through this elaboration a more general account will be developed of mediatization as a dialectical process that integrates interveillance as a key feature and increasingly promi-

advanced political actions and artistic interventions that aim to strengthen the power and communion of "ordinary citizens". While partly related, the concept covers a different set of practices and different social dynamics than the horizontal forms of everyday monitoring discussed here. nent social force behind the current escalation of everyday media dependence.

\section{Interveillance and Simulated Recognition}

First of all we must specify what recognition means and why it has become a critical issue in modern society. Honneth (2012), who takes his key from psychoanalytical theory, sees recognition as a basic requirement for the individual to establish a sense of security in his or her capability of thinking, reflecting and acting independently of other individuals. Such a sense of autonomy cannot emerge without the positive attention from significant others, who contribute to both social integration and a sense of individual worth on behalf of the individual. The individual's desire to belong to groups is thus not merely a reflection of integrative forces, but should be understood as a quest for autonomy through recognition. One of the predicaments of Honneth's theory of recognition is that "groups should be understood, whatever their size or type, as a social mechanism that serves the interests or needs of the individual by helping him or her to achieve personal stability and growth" (Honneth, 2012, p. 203). However, the membership of groups gives no guarantee for recognition in the true sense of the word, since groups may also involve repressive tendencies that rather lead to conformism and the dissolution of autonomy.

In Honneth's positive definition of the term, recognition "should be understood as a genus comprising various forms of practical attitudes whose primary intention consists in a particular act of affirming another person or group" (Honneth, 2012, pp. 80-81). The concept thus contains three basic premises: recognition should be (1) positively affirmative, (2) actualized through concrete action (rather than just symbolical in nature), and (3) explicitly intended (rather than emerging as a social side effect or means for reaching other goals). It is also stated that the basic attitude of recognition can take the form of different "sub-species", notably love, legal respect and esteem. Against such pure stances of recognition Honneth poses ideological forms of recognition that rather exploit the individual's psychosocial needs in order to install attitudes that reproduce certain structures of domination. One example is the way in which societies of different epochs have endorsed certain attributes among certain groups (based on gender, sexuality, ethnicity, and so on) as part of the reproduction of hegemonic orders for the division of labour: "We could easily cite past examples that demonstrate just how often public displays of recognition merely serve to create and maintain an individual relation-to-self that is seamlessly integrated into a system based on the prevailing division of labour" (Honneth, 2012, p. 77). Such ideological forms of recognition are false, Honneth argues, because they fail to promote personal autonomy. 
Recognition theory has so far gained very little attention within media studies, and vice versa. ${ }^{2}$ In my view, Honneth's thinking around recognition lays the ground for a broader social critique of how the expansion of interveillance resonates with structural transformations. His analyses point especially to the negative consequences of an extended individualization process, including forces that under the auspices of supporting autonomy and recognition actually operate in the opposite direction. Whereas individualization in its positive fulfilment sets individuals free from oppressive structures and normalizes the pluralization of choice it also leads to a state of increased psychological anxiety and vulnerability among individuals, which in turn can be seen as "one, if not the, central motive behind group formation today" (Honneth, 2012, p. 207). Since modern society, as opposed to more traditional formations, does not provide one unified standard (such as religiously grounded ethics) in relation to which the individual may estimate the value of his or her achievements, it becomes increasingly important for the individual to achieve recognition within the peer group. Furthermore, media institutions, labour markets and a multitude of commercial and political actors promote individuals to actively work on their identities and learn how to present their personalities in ways that are as beneficial as possible for reaching certain goals in society or in their careers. Honneth (2004, 2012, Ch. 9) calls this organized self-realization, which implies that self-realization becomes ideologically normalized as a biographical goal. Genuinely dialogical processes of recognition are undermined and replaced by standardized patterns of identity-seeking and simulated forms of recognition that serve the goal of legitimizing and further integrating individuals into the capitalist system. Authenticity and autonomy transmute into their opposites, simulation and conformism, and individuals may ultimately find their lives devoid of meaning.

We can now discern the connection to interveillance. What Honneth outlines is a dialectical transformation whereby the individual quest for recognition and autonomy rather leads to the legitimation of and dependence on various technological and economic

\footnotetext{
2 On the whole, recognition theory attains a strong political and social philosophical bias. In a recent volume entitled Recognition Theory as Social Research (O'Neill \& Smith, 2012), in spite of the broad scope of the book, none of the eleven chapters addresses the pervasive role of media for shaping contemporary relations of recognition. In media and communication studies the work by Nancy Fraser (e.g., 2000, 2001) has gained substantial attention among scholars studying for instance the politics of identity and migration. The most significant work that has brought together questions of recognition and mediation is Boltanski's (1996/1999) book Distant Suffering. This work deals chiefly with spectatorship, however, and is linked to questions of pity and self-justification in the age of mass mediated humanitarian spectacles.
}

systems (see also, e.g., Beck \& Beck-Gernsheim, 2002; Boltanski \& Chiapello, 1999/2007; Giddens, 1991). Honneth does not pay much attention to media technologies and institutions, however. To the extent they are mentioned, they are taken as a compound institution, "electronic media" (Honneth, 2012, p. 162), that operates as a machinery for normalizing desirable formats of selfrealization through for example advertising and popular fiction, which play the role of legitimizing certain ideological forms of recognition. This diagnosis resonates in interesting ways with Riesman's (1950/2001) account of how other-directedness spread as the dominant mode of social conformity in post-war America, involving reflexive forms of lifestyle management among the urban middle classes. The desire to achieve mutual recognition among peers was channelled through standardized consumption practices whose symbolic meanings were socially implanted via mass media.

The mass media system thus operates both as a map and a guidebook of the social terrain; a system that establishes and negotiates the codes through which patterns of interpersonal recognition (and misrecognition) evolve. This means that mass media not only mediate but also, and perhaps more significantly, premediate social expectations and experiences of individual actors (Grusin, 2010), turning the process of (mass) mediation per se into a force of symbolic legitimation. What (and who) is mediated is what counts as important. As Couldry (2003) suggests, the symbolic power of media (taken in the broad, institutional sense) rests on a dominant mythology that constructs the media as an institution that circulates symbolic material possessing exceptional social, cultural, economic and/or political significance. This mythology functions as a stabilizing factor in relation to the social anxieties articulated through organized self-realization, and legitimizes people's ritualized dependence on mass media as a structure of premediated recognition.

Today we must rethink these relations. The widespread usage of social media, mobile devices and numerous transmedia applications has in recent years come to play into the social functions of mass media, both challenging and extending them. A growing share of media users, especially younger groups, orient their media habits towards interactive platforms, such as Facebook and YouTube, that circulate user-generated flows as well as content emanating from mass media industries. $^{3}$ As Gillespie (2010, p. 347) argues, these platforms have become the "curators of public discourse". They both enable and demand continuous monitoring and updating, and thus feed off precisely

\footnotetext{
3 In Sweden, for instance, one of the leading countries in this development, more than 50 per cent of young Internet users (ages 12-18 years) use YouTube every day and more than 50 per cent of Internet users between 20 and 45 years old use YouTube every week (Findahl, 2014).
} 
those psychosocial needs and desires that characterize other-directed life environments, while at the same time extending the pre-established mythology of institutionalized mediation as a marker of socio-cultural status. Accordingly, dominant social media build their success upon the promises of providing solutions to recognition deficit, but contribute at the same time to the reinforcement of interveillance culture through the circulation of simulated forms of recognition, which now exist alongside various premediated forms.

This is not to say that all forms of interaction that occur via dominant social media resonate with the industrially invoked logics of popularity scores and simulations of connectedness, or that all forms of recognition on these platforms are of an ideological nature. It is not to say that connective practices, such as liking, commenting and (geo)tagging, are always to be seen as mere expressions of interveillance and cannot be part of deeper relations of recognition, such as love, friendship or identity politics, or make up community maintaining flows of phatic communication (see, e.g., Ling, 2008; Miller, 2008). However, the architecture of dominant social media and the interfaces through which interveillance unfolds sustain open-ended processes of simulation where the distinction between connectivity and connectedness is collapsed (van Dijck, 2013). For instance, whereas algorithmic systems keep track of how many connections (friends, followers, etc.) different users have and how many confirmative acts certain posts generate, these functionalities contradict the dialogical aspects that mark pure forms of recognition and make it possible for each actor to hermeneutically assess and build trust in the intentionality and practical relevance of other communicators' symbolic acts (cf. Striphas, 2015). On the contrary, social media relations are typically marked by uncertainty as to what intentions and what level of involvement may hide behind the digital interface, that is, what is "actually" going on.

This mediated social uncertainty, which can be identified in areas as diverse as political action (e.g., related to microblogging) and intimate relations (e.g., dating sites), is exactly what characterizes and reinforces the culture of interveillance. In interveillance there is never any affirmative dialogue. In interveillance, recognition is continuously at stake, but never achieved.

In this section, an explanation has been provided of how the expanding industrial logics of social media interact with long-term social transformations of individualized societies. The overarching point is that dominant social media contribute to the normalization of simulated forms of recognition, which establishes interveillance as a ritualized part of everyday life and makes certain media devices and applications ritually indispensable to social life. At the same time, however, we should embrace the fact that the overall consequences of interveillance are ambiguous and take on different (often contradictory) appearances in different contexts. We should also take into account that interveillance is intertwined with and inseparable from deeper forms of mutual recognition and emancipatory forms of communication that take place between peers through a variety of media (e.g., Caughlin \& Sharabi, 2013; Jiang \& Hancock, 2013; Linke, 2011).

When raising critical questions concerning the social and existential costs of our connected lives we should thus move beyond simplified views of social fragmentation and media power. Rather, the type of social and cultural critique that should be considered is of an immanent nature (see, e.g., Fornäs, 2013). The purpose of immanent critique is precisely to grasp the contradictions and ambiguities that characterize social transformations on both individual and structural levels, and explore how these levels are interrelated. In the following section I will discuss the ways in which the culture of interveillance may signify a new stage within the broader dialectical meta-process of mediatization.

\section{Interveillance and the Dialectics of Mediatization}

Two main points have so far been advanced. Firstly, it has been described how interveillance is related to the social relocation of media, including the growing prominence of dominant social media, and argued that we need to maintain analytical distinctions between interveillance and surveillance (Table 1). Secondly, it has been argued that the emerging culture of interveillance, and its variations, can only be sufficiently understood if we account for how the industrial logics of social media resonate with social forces already at play in individualized societies, above all the increasingly open-ended quest for recognition. This is where we find the fundamental energy that drives and entertains the commercial machineries of dominant social media, which in turn occupy an increasingly significant role in normalizing partly new ways of defining social relations and senses of self (notably in terms of connectivity and popularity). The culture of interveillance thus arises through the mutual operation of social and technoeconomic forces. It denotes a cultural condition where identity creation is saturated with monitoring practices based on simulations of connectedness and recognition, thus reproducing the ambiguities of recognition they were intended to stabilize.

What follows from this is my third and concluding point; the culture of interveillance both integrates and reinforces the dialectics of mediatization. The term mediatization refers to something more than just the general development and appropriation of more media within more areas of social life. While such quantitative elements are indeed part and parcel of the mediatization meta-process, as Hepp (2013) points out, we can only estimate the real force of mediatization once we are able to detect substantial social and cultural trans- 
formations tied to the establishment of new media technologies as cultural forms (Williams, 1974; see also Hjarvard \& Nybro Petersen, 2013). When this happens, as it did with radio and television during the broadcasting era, media are experienced as more or less indispensable and social life becomes difficult to manage, and indeed to imagine, without them. During a long period of the $20^{\text {th }}$ century, and still today, modern life was spatially and temporally ordered in relation to the material and cultural properties of these media (see, e.g., Scannell, 1996; Spigel, 1992). While broadcasting, taken as one institution, enabled new forms of social extension and functioned as a (pre)mediator of recognition, as discussed above, it also established (more or less context specific) dependencies vis-à-vis certain flows of information and certain technologies.

In a similar manner, the culture of interveillance encompasses the normalization of a new set of everyday media routines and the taken-for-grantedness of certain media ensembles - such as, smartphones, tablets, Wi-Fi networks and social media accounts. Interveillance practices, as we have seen, are thoroughly interwoven with other kinds of everyday practices and are rarely systematic or strategic in nature. They come to surface as "something one just does", while on the move or while waiting, during free time or while pursuing other routines. They are also interwoven with other online activities (news gathering, shopping, gaming, and so forth), which together contribute to the social construction of media as indispensable things (Jansson, 2014b). There are several empirical studies showing that a life without mobile media devices and various social media applications would be more or less unthinkable to many social groups today and that people even develop counter-routines in order to cope with their experiences of being increasingly "addicted" to keeping an eye on various information flows and updates, responses to things they have posted online and the fluctuations of social media scores (e.g., Bengtsson, 2015; Hall \& Baym, 2012; Paasonen, 2014).

Dependencies may also be of a more formal, transactional nature. As we have already seen, the basically horizontal processes of interveillance are structurally integrated with vertical processes of automated commercial surveillance. This means that each user of an online service has to subscribe to terms and conditions that allow the service provider to aggregate, store and analyze data flows in order to build consumer segments for targeted online advertising, that is, to maintain the industrial logics. The kinds of recognition that may stem from such personalized services and publicity offers are ideological in the sense that they contribute to the legitimation of the dominant system itself rather than to individual autonomy (following Honneth, 2012). Whereas this means that many social media sites (such as Facebook and YouTube) to some extent occupy the same symbolically orienting function as the mass media, being part of the premediation of social relations and identities, they are at the same time transforming these conditions through turning individual media users, or prosumers, into agents of their own surveillance. They are explicitly complying with substantial privacy restraints, whose character and implications they often find obscure and/or difficult to penetrate (Andrejevic, 2007, 2014). Previous research shows that most media users feel less anxious in relation to this type of systematic surveillance than in relation to interveillance practices (see Marwick, 2012; Taddicken, 2012; Jansson, 2012) but also tend to overlook the actual terms of use that they sign (Best, 2010; Andrejevic, 2014). What may seem like a space of recognition is thus literally turned into a space of transactional dependence and "infinite debt" (Andrejevic, 2014), which in turn reproduces the functional dependence vis-à-vis various technological systems and infrastructures.

Mediatization is thus a complex transformative force that integrates both a liberating potential, the prospects of greater autonomy and new avenues towards social recognition enabled by media, and new forms of dependence that in different ways restrict the prospects of liberation. The dialectical relations between these two sides vary over time and depend on socio-cultural as well as media-specific factors that have to be identified empirically. The point that has been outlined in this essay, via the concept of interveillance, is just one yet increasingly prominent expression of the dialectics of mediatization. We may even say that this represents a new face, or a new stage, of mediatization. In this analysis the fact that mediatization processes are characterized by a complex, and contextually dependent, interplay between industrial logics and more enduring social transformations has been highlighted. If we want to formulate an immanent critique of why a growing share of the world's population allows their lives and identities to get entangled with increasingly complex technological and commercial structures of surveillance we should take this interplay into consideration-and thus also transcend the divide between institutional and social-constructivist perspectives on mediatization.

\section{Acknowledgments}

This article is part of the ongoing research project "Cosmopolitanism from the Margins: Mediations of Expressivity, Social Space and Cultural Citizenship", funded by the Swedish Research Council (2012-2015). The author would like to thank Miyase Christensen, Karin Fast and Johan Lindell for valuable discussions and comments on earlier versions of this text, as well as the anonymous reviewers for their very constructive critique. 


\section{Conflict of Interests}

The author declares no conflict of interests.

\section{References}

Albrechtslund, A. (2008). Online social networking as participatory surveillance. First Monday 13(3).

Andrejevic, M. (2005). The work of watching one another: Lateral surveillance, risk, and governance. Surveillance and Society, 2(4), 479-497.

Andrejevic, M. (2007). ispy: Surveillance and power in the interactive era. Lawrence: University Press of Kansas.

Andrejevic, M. (2014). The infinite debt of surveillance in the digital economy. In A. Jansson \& M. Christensen (Eds.), Media, surveillance and identity: Social perspectives (pp. 91-108). New York: Peter Lang.

Beck, U., \& Beck-Gernsheim, E. (2002). Individualization: Institutionalized individualism and its social and political consequences. London: Sage.

Bengtsson, S. (2015). An ethics of ambiguity in a culture of connectivity? Paper presented at the international research workshop Mediatisation of Culture and Everyday Life, 23-24 April 2015, Stockholm, Sweden.

Best, K. (2010). Living in the control society: Surveillance, users and digital screen technologies. International Journal of Cultural Studies, 13(1), 5-24.

Boltanski, L. (1996/1999). Distant suffering: Morality, media and politics. Cambridge: Cambridge University Press.

Boltanski, L., \& Chiapello, E. (1999/2007). The new spirit of capitalism. London: Verso.

Caughlin, J. P., \& Sharabi, L. L. (2013). A communicative interdependence perspective of close relationships: The connections between mediated and unmediated interactions matter, Journal of Communication, 63(5), 873-893.

Christensen, M. (2014). Complicit surveillance and mediatized geographies of visibility. In A. Jansson \& $\mathrm{M}$. Christensen (Eds.), Media, surveillance and identity: Social perspectives (pp. 15-31). New York: Peter Lang.

Couldry, N. (2003). Media rituals: A critical approach. London: Routledge.

Couldry, N., \& Hepp, A. (2013). Conceptualizing mediatization: Contexts, traditions, arguments. Communication Theory, 13(3), 191-202.

Deacon, D., \& Stanyer, J. (2014). Mediatization: Key concept or conceptual bandwagon? Media, Culture \& Society, 36(7), 1032-1044.

Findahl, O. (2014). Svenskarna och Internet 2014. Stockholm: SE (Stiftelsen för Internetinfrastruktur).

Fornäs, J. (2013). The dialectics of communicative and immanent critique in cultural studies. TripleC, 11(2), 504-514.
Foucault, M. (1977). Discipline and punish. New York: Knopf Doubleday Publishing Group.

Fraser, N. (2000). Rethinking recognition. New Left Review, 3(May-June 2000), 107-120.

Fraser, N. (2001). Recognition without ethics? Theory, Culture and Society, 18(2-3), 21-42.

Fuchs, C. (2014). Social media: A critical introduction. London: Sage.

Giddens, A. (1987). The nation-state and violence: Volume two of a contemporary critique of historical materialism. Berkeley: University of California Press.

Giddens, A. (1991). Modernity and self-identity: Self and society in the late modern age. Cambridge: Polity Press.

Gillespie, T. (2010). The politics of "platforms". New Media \& Society, 12(3), 347-364.

Grusin, R. (2010). Premediation: Affect and mediality after 9/11. Basingstoke: Palgrave Macmillan.

Hall, J. A., \& Baym, N. K. (2012). Calling and texting (too much): Mobile maintenance expectations, (over)dependence, entrapment, and friendship satisfaction. New Media and Society, 14(2), 316-331.

Hepp, A. (2013). Cultures of mediatization. Cambridge: Polity Press.

Hepp, A., Hjarvard, S., \& Lundby, K. (2015). Mediatization: Theorizing the interplay between media, culture and society. Media, Culture \& Society, 37(2), 314-324.

Hjarvard, S. (2013). The mediatization of culture and society. London: Routledge.

Hjarvard, S., \& Nybro Petersen, L. (2013). Mediatization and cultural change. MedieKultur, 54, 1-7.

Honneth, A. (2004). Organized self-realization: Some paradoxes of individualization, European Journal of Social Theory, 7(4), 463-478.

Honneth, A. (2012). The I in the we: Studies in the theory of recognition. London: Polity Press.

Humphreys, L. (2011). Who's watching whom? A study of interactive technology and surveillance. Journal of Communication, 61(4), 575-595.

Jansson, A. (2012). Perceptions of surveillance: Reflexivity and trust in a mediatized world (the Case of Sweden). European Journal of Communication, 27(4), 410-427.

Jansson, A. (2013). Mediatization and social space: Reconstructing mediatization for the transmedia age. Communication Theory, 23(3), 279-296.

Jansson, A. (2014a). Textures of interveillance: A sociomaterial approach to the integration of transmedia technologies in domestic life. In A. Jansson \& $\mathrm{M}$. Christensen (Eds.), Media, surveillance and identity: Social perspectives (pp. 145-162). New York: Peter Lang.

Jansson, A. (2014b). Indispensible things: On mediatization, space and materiality. In K. Lundby (Ed.), Mediatization of communication (Handbook of communication sciences, vol. 22) (pp. 273-295). Berlin: 
De Gruyter Mouton.

Jansson, A. (forthcoming). The moulding of mediatization: The stratified indispensability of media in close relationships, Communications.

Jiang, L. C., \& Hancock, J. T. (2013). Absence makes the communication grow fonder: Geographic separation, interpersonal media, and intimacy in dating relationships, Journal of Communication, 63(3), 556577.

Krotz, F. (2007). The meta-process of "mediatization" as a conceptual frame. Global Media and Communication, 3(3), 256-260.

Ling, R. (2008). New tech, new ties: How mobile communication is reshaping social cohesion. Cambridge, MA: MIT Press.

Linke, C. (2011). Being a couple in a media world: The mediatization of everyday communication in couple relationships. Communications, 36(1), 91-111.

Lundby, K. (2014). Mediatization of communication. In $\mathrm{K}$. Lundby (Ed.), Mediatization of communication (Handbook of communication sciences, vol. 22) (pp. 3-35). Berlin: De Gruyter Mouton.

Lyon, D. (2007). Surveillance studies: An overview. Cambridge: Polity Press.

Marwick, A. E. (2012). The public domain: Social surveillance in everyday life. Surveillance \& Society, 9(4), 378-393.

Marwick, A. E. (2013). Status update: Celebrity, publicity and branding in the social media age. New Haven, CT: Yale University Press.

Marwick, A. E., \& boyd, d. (2011). I tweet honestly, I tweet passionately: Twitter users, context collapse, and the imagined audience. New Media and Society, 13(1), 114-133.

Miller, V. (2008). New media, networking and phatic culture. Convergence, 14(4), 387-400.

O'Neill, S., \& Smith, N. H. (Eds.) (2012). Recognition theory as social research: Investigating the dynamics of social conflict. Basingstoke: Palgrave Macmillan.
Paasonen, S. (2014). As networks fail: Affect, technology, and the notion of the user. Television \& New Media. doi:10.1177/1527476414552906

Riesman, D. (1950/2001). The lonely crowd. New Haven: Yale University Press.

Scannell, P. (1996). Radio, television and modern life. Oxford: Blackwell.

Spigel, L. (1992). Make room for TV: Television and the family ideal in postwar America. Chicago: University of Chicago Press.

Striphas, T. (2015). Algorithmic culture. European Journal of Cultural Studies, 18(4-5), 395-412.

Taddicken, M. (2012). Privacy, surveillance, and selfdisclosure in the social web: Exploring the user's perspective via focus groups. In C. Fuchs, K. Boersma, A Albrechtslund, \& M. Sandoval (Eds.), Internet and surveillance: The challenges of Web 2.0 and social media (pp. 255-271). London: Routledge.

Trottier, D. (2011). A research agenda for social media surveillance. Fast Capitalism, 8(1).

Trottier, D., \& Lyon, D. (2012). Key features of social media surveillance. In C. Fuchs, K. Boersma, A. Albrechtslund, \& M. Sandoval (Eds.), Internet and surveillance: The challenges of Web 2.0 and social media (pp. 89-105). London: Routledge.

Turkle, S. (2011). Alone together: Why we expect more from technology and less from each other. New York: Basic Books.

van Dijck, J. (2012). Facebook as a tool for producing sociality and connectivity. Television and New Media, 13(2), 160-176.

van Dijck, J. (2013). The culture of connectivity: A critical history of social media. Oxford: Oxford University Press.

van Dijck, J., \& Poell, T. (2013). Understanding social media logic. Media and Communication, 1(1), 2-14.

Williams, R. (1974). Television: Technology and cultural form. London: Fontana.

Wittel, A. (2001). Toward a network sociality. Theory, Culture \& Society, 18(6), 51-76.

\section{About the Author}

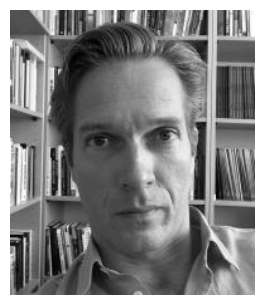

Dr. André Jansson

André Jansson is Professor of Media and Communication Studies at Karlstad University, Sweden. His research deals primarily with questions of mediatization, identity and social space. His most recent books are Cosmopolitanism and the media (2015, co-authored with Miyase Christensen) and Media, surveillance and identity (2014, co-edited with Miyase Christensen). Recent articles have appeared in journals like Communication Theory, International Journal of Cultural Studies, MedieKultur, New Media and Society and Space and Culture. 